\title{
OPERAÇÃO RONDON: REALIDADE AUMENTADA DO PROJETO MUSEU VIRTUAL APLICADA NA EDUCAÇÃO INFANTIL
}

\author{
Hugo Leonardo Petla Silva \\ Universidade Estadual de Ponta Grossa \\ hugopetla@hotmail.com \\ Diolete Marcante Lati Cerutti \\ Universidade Estadual de Ponta Grossa \\ diolete@uepg.br
}

\author{
Tatiana Montes Celinski \\ Universidade Estadual de Ponta Grossa \\ tmcenlinski@gmail.com \\ Frederico Guilherme Ielo \\ Universidade Estadual de Ponta Grossa \\ fgielo@uepg.br
}

\section{Resumo \\ Este artigo tem por objetivo apresentar os resultados das atividades realizadas com as escolas públicas do município de São José da Boa Vista, através da Operação Rondon com a realização de uma oficina para apresentar uma nova ferramenta didática com Realidade Aumentada e também mostra a evolução dos computadores e de seus equipamentos para nova geração de usuários. Foram realizadas oficinas no município de São José da Boa Vista nos dias 22, 23 e 24 de julho de 2015 com a aplicação de Realidade Aumentada desenvolvida no projeto de extensão Museu da Computação da UEPG em escolas com alunos entre cinco a doze anos. A Realidade Aumentada se mostrou eficiente e atrativa na educação e apoio a materiais convencionais de estudo, ajudando até mesmo na educação especial. \\ Palavras-chave: Educação. Interatividade. Materiais pedagógicos baseados em computador \\ OPERAÇÃO RONDON: AUGMENTED REALITY OF VIRTUAL MUSEUM OF APPLIED PROJECT IN EARLY CHILDHOOD EDUCATION}

\begin{abstract}
This article has the objective to present the results of activities carried out with public schools in São José da Boa Vista by the Operação Rondon with the realization of a workshop to present a new teaching tool with Augmented Reality and also shows the evolution of computers and their equipament to the new generation of computer users. Workshops were held in São José da Boa Vista on July 22, 23 and 24 of 2015 with the application of Augmented Reality developed on the extension project UEPG Museum of Computing in schools with pupils aged five to twelve years old. Augmented Reality proved it is a efficient and attractive on the education and support for conventional study materials, helping even in special education. Keywords: Education. Interactivity. Teaching materials based on computer
\end{abstract}

\section{OPERAÇÃO RONDON: REALIDAD AUMENTA DEL PROYECTO MUSEU VIRTUAL DE APLICACIÓN EN LA EDUCACIÓN DE LA PRIMERA INFANCIA}

\section{Resumen}

Este artigo tiene por objetivo presentar los resultados de las actividades realizadas con las escuelas públicas del municipio de São José da Boa Vista a través da Operação Rondon con la celebración de un taller para presentar una nueva herramienta didacta con Realidade Aumenta y también muestra la evolución de los ordenadores y sus equipamientos para nueva generación de usuarios de ordenadores. Fueran realizadas oficinas en el municipio de São José da Boa Vista en los días 22,23 y 24 de julio de 2015 con la aplicación de Realidade Aumenta desarrollada en el proyecto de extensión Museu da Computação da UEPG en escuelas con alumnos entre cinco y doce años. La Realidad Aumentada se mostró eficiente y atractiva en la educación y apoyo a materiales convencionales de estudio, ayudando hasta mismo en la educación especial. Palavras clave: Educación. Interactividad. Los materiales didácticos informáticos basados 
Operação Rondon: realidade aumentada do projeto museu virtual aplicada na educação infantil

\section{INTRODUÇÃO}

Realidade Aumentada (RA) é uma linha de pesquisa dentro da ciência da computação que lida com integração do mundo real e elementos virtuais ou dados criados pelo computador. Atualmente, a maior parte das pesquisas em RA está ligada ao uso de vídeos transmitidos ao vivo, que são digitalmente processados e "ampliados" pela adição de gráficos criados pelo computador. Pesquisas avançadas incluem uso de rastreamento de dados em movimento, reconhecimento de marcadores confiáveis utilizando mecanismos de visão, e a construção de ambientes controlados contendo qualquer número de sensores e atuadores. Uma definição aceita sobre RA é a de Azuma(1997), onde ele diz que "Realidade Aumentada é um ambiente que envolve tanto realidade virtual como elementos do mundo real, criando um ambiente misto em tempo real". Azuma(1997) transmite a ideia de que a Realidade Aumentada utiliza elementos reais e virtuais que são combinados em tempo real e que formam imagens em três dimensões interativas.

Existem atualmente quatro sistemas de utilização de realidade aumentada (Azuma, 2001), classificados segundo a interface utilizada(Kirner,2005). A descrição utilizada como base para este estudo segue a terceira definição proposta por Azuma(2001): Sistema de visão por vídeo baseado em monitor: Essa é a técnica mais conhecida, onde a imagem real é capturada por uma Webcam (câmera de vídeo apropriada para o uso em microcomputadores) e transmitida pelo monitor, já com os objetos virtuais inseridos.

A utilização de materiais didáticos, principalmente livros impressos, mostra-se capaz de suprir boa parte da necessidade encontrada na aprendizagem. Porém, há uma grande brecha para o ensino de forma prática devido a sua monotonia ao transmitir um conhecimento. É amplamente discutida a utilização de tecnologias em sala de aula, para que uma solução não seja considerada falsamente boa para o ensino. Segundo Biagini(2012), que discutiu a viabilidade pedagógica da RA em um projeto de extensão, observa que "a ferramenta mostrou-se adequada para o trabalho proposto, pois o software é adaptável e permite o teste de viabilidade da tecnologia, como também o reuso destas aplicações em outros contextos".

Utilizar uma tecnologia substituindo materiais já conhecidos e sem a verificação da sua efetividade, para apenas utilizar uma tecnologia, não são soluções para a informatização das escolas. A atividade realizada tem caráter de verificar a utilização da tecnologia de Realidade Aumentada aliada a materiais para educação infantil em escolas fundamentais e especiais. 
Operação Rondon: realidade aumentada do projeto museu virtual aplicada na educação infantil

\section{MATERIAIS E MÉTODOS}

\section{Aplicativo}

Primeiramente foi utilizado para realização das oficinas o ARToolKit por alunos do programa de extensão Museu da Computação da UEPG(Universidade Estadual de Ponta Grossa), para desenvolver um software com Realidade Aumentada. Para a aplicação criada pelo museu, foram confeccionados marcadores que se correspondiam com imagens em 3D. Entre esses marcadores haviam imagens ou animações randômicas, ou imagens correspondentes a equipamentos eletrônicos antigos e atuais, como mostra a Ilustração 1.

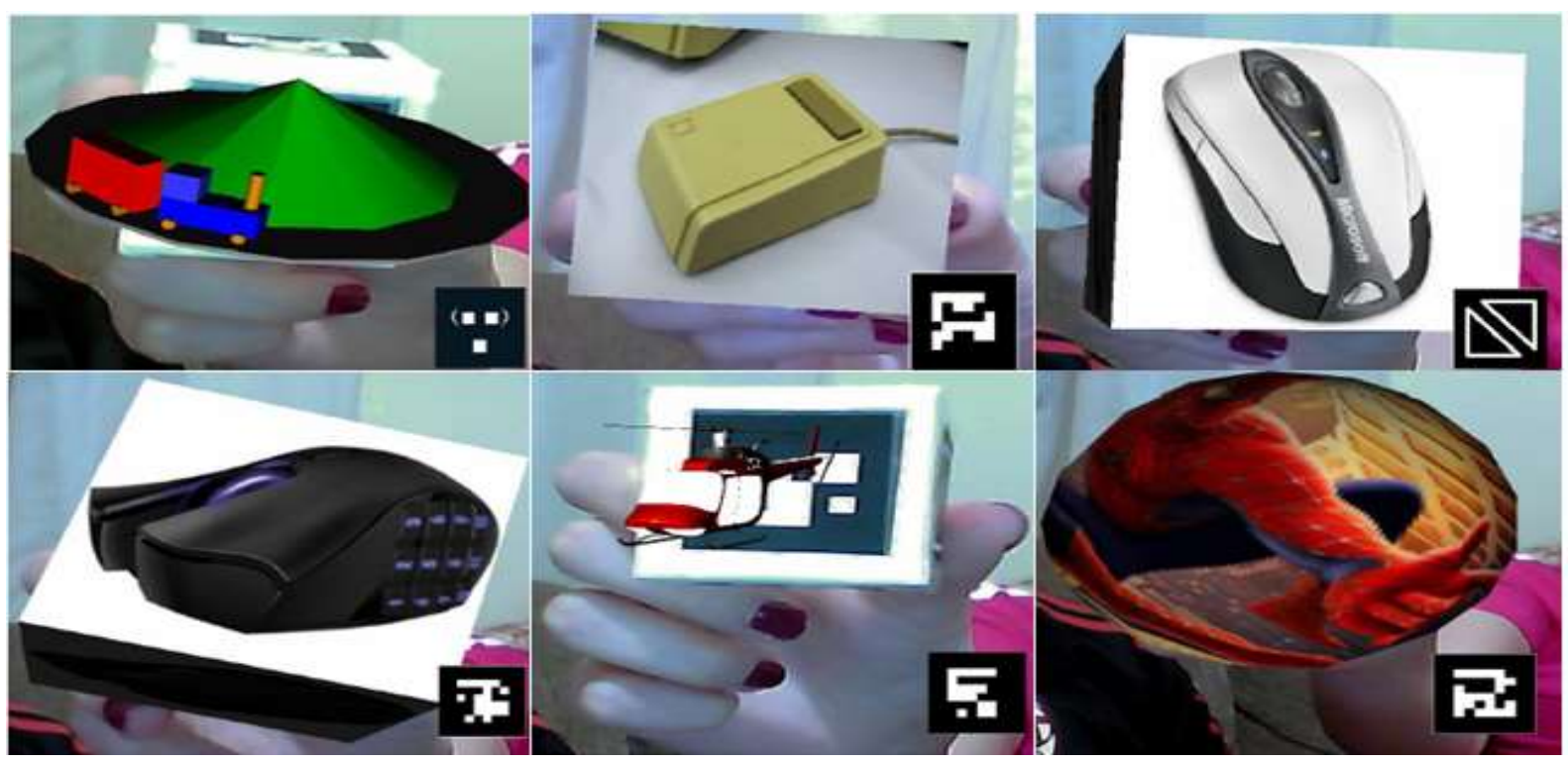

Ilustração 1 - Exemplos de marcadores e suas imagens correspondentes. Fonte: Biagini, 2015.

Os marcadores foram colocados em cubos. Em cada cubo há três imagens de equipamentos iguais, mas com diferenças na data de criação; e outras três aleatórias conforme mostra a Ilustração 2. 


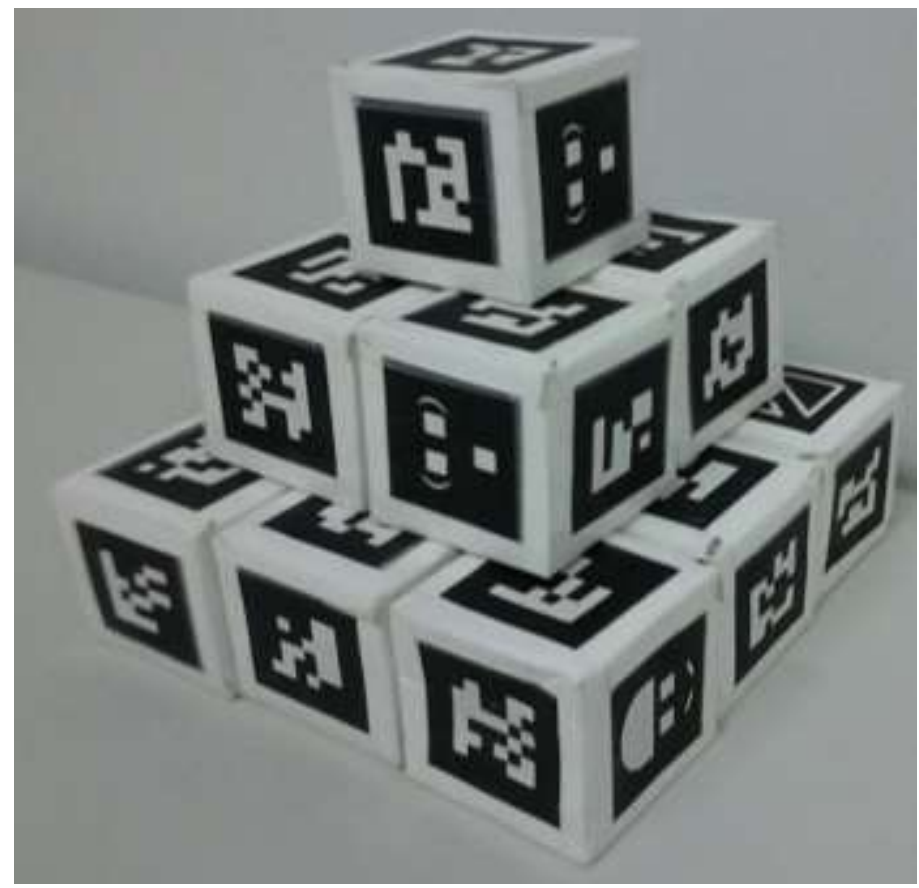

Ilustração 2 - Cubos confeccionados contendo marcadores de Realidade Aumentada. Fonte: Elaborado pelos autores, 2015.

Para realizar a atividade é necessário um computador. Não é necessário instalar a aplicação, pois ela é leve e em formato de programa executável, com Webcam para reconhecer os marcadores e transformar nas imagens 3D correspondentes. $\mathrm{O}$ intuito da aplicação é mostrar a nova tecnologia de RA e utilizá-la para ensino. Neste caso, mostrar como o computador e seus dispositivos eram antigamente, já que o grande avanço dessa área torna difícil para a nova geração populacional que utiliza equipamentos modernos imaginar como eram os antepassados do computador.

\section{Aplicação das oficinas}

Para realizar a atividade foram utilizados dois computadores com a aplicação de Realidade Aumentada e com Webcam. As oficinas tinham duração de trinta minutos em média. Os dez primeiros minutos eram utilizados para apresentações e explicação sobre Realidade Aumentada. Os quinze minutos seguintes eram utilizados para a parte prática da oficina, onde a turma foi dividida em duas equipes, que recebiam sete cubos cada para verificar as imagens contidas nos marcadores dos cubos e discutirem entre si o que eles conseguiram encontrar entre as imagens. Nos cinco minutos finais a turma foi reunida novamente e foi feito um levantamento do que eles conseguiram verificar entre as imagens. Após alguns alunos comentarem sobre as tecnologias encontradas foi discutido se todos conheciam aquele equipamento e sua evolução. Nos casos da 
Operação Rondon: realidade aumentada do projeto museu virtual aplicada na educação infantil

realização da oficina com alunos especiais foi feita a explicação de forma mais breve e aumentado o tempo na parte prática.

\section{As escolas participantes}

As oficinas foram realizadas no município de São José da Boa Vista nos dias 22, 23 e 24 de Julho de 2015. O apresentador da Oficina era o aluno Hugo Leonardo Petla Silva, aluno de Engenharia de Computação, acompanhado em diferentes turmas por um ajudante que fazia parte do grupo da Operação São José da Boa Vista.

Foram realizadas oficinas para alunos em uma faixa etária de cinco a doze anos em dezesseis turmas da Escola Municipal Francisco Abílio, sendo uma de alunos especiais com déficit de atenção e similares - em duas turmas da Escola Municipal Anesia Dias e em uma turma da Escola Estadual Jose de Alencar, localizada no distrito da Mangueirinha, e para três turmas da Escola APAE(Associação de Pais e Amigos dos Excepcionais) São Miguel, a qual possui alunos com diversos tipos de síndromes e déficit de atenção. Entre eles há também um aluno cadeirante e com dificuldade de locomoção. Cada turma tinha em média vinte alunos, exceto as turmas da Mangueirinha que tinham em média dez alunos por turma e as turmas da APAE, que foram reunidas nas três salas para aumentar o número de alunos.

\section{RESULTADOS E ANÁLISES}

O trabalho realizado obteve sucesso na explanação sobre a evolução do computador e seus equipamentos. A Realidade Aumentada se mostrou uma ferramenta útil para o processo de ensino-aprendizagem, pois gera interesse em verificar o que há nos marcadores e dessa forma otimiza o tempo de ensino, já que de uma forma prática e divertida o professor/orientador pode explicar diversos conteúdos. A Ilustração 3 mostra os alunos e os rondonistas interagindo com o aplicativo através dos cubos. 


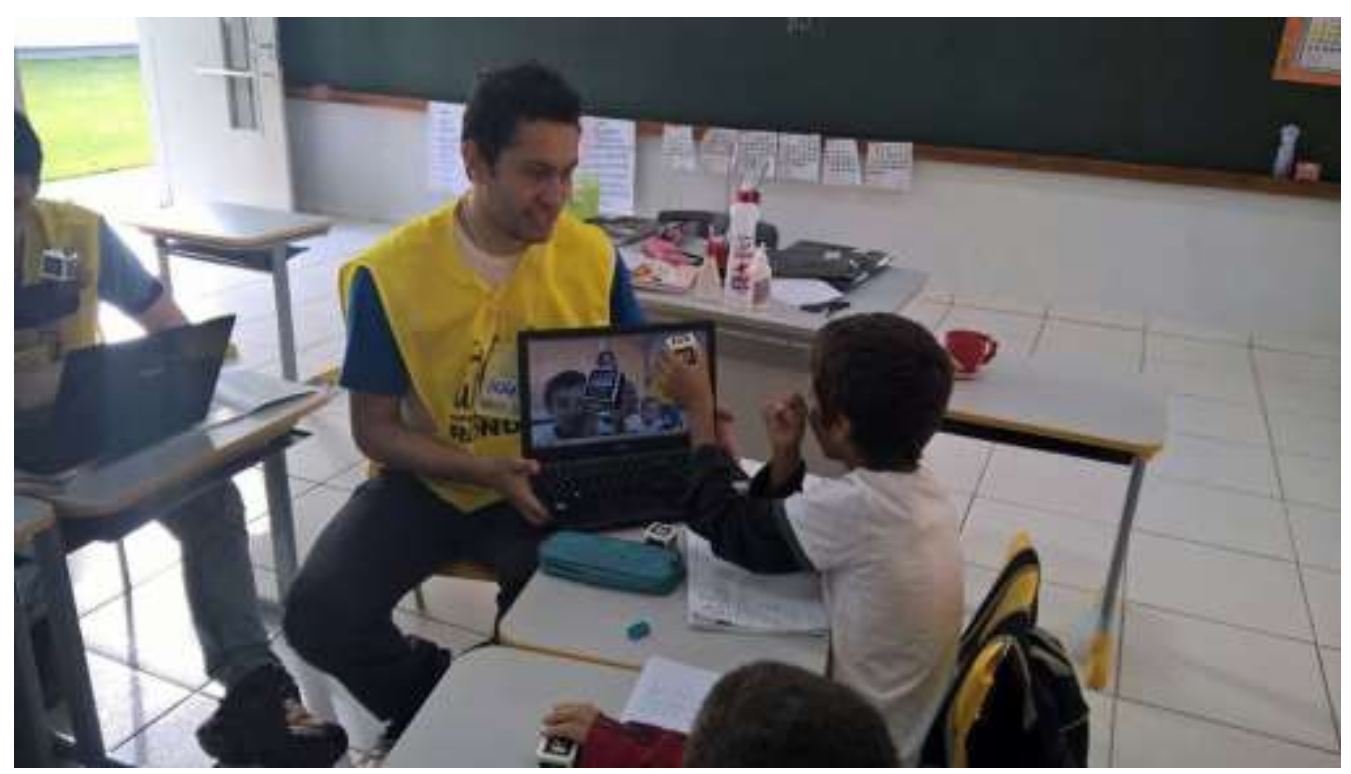

Ilustração 3 - Interatividade dos alunos com a ferramenta utilizando os cubos de marcadores. Fonte: Elaborado pelos autores, 2015.

Houve um interesse maior para alunos com idades entre cinco a oito anos e alunos da APAE. Isto poderia gerar oportunidades para desenvolver aplicações que possam ajudar em contação de histórias, alfabetização, ensino de cores e formas geométricas e matemática básica. Houve comentários dos alunos como "O que você colocou dentro desse cubo professor? Eu sei que tem algo ai dentro para fazer ele funcionar", mostrando que não é necessário ter conhecimentos sobre computação para realizar a atividade proposta e aprender algo através dessa tecnologia.

É possível observar que com apenas uma Webcam dentre os periféricos de um computador para realizar a atividade, até mesmo pessoas com algum limite para se movimentar, como foi observado na APAE, conseguiram realizá-la de maneira satisfatória.

Foi observado um caso na escola do distrito da Mangueirinha em que um aluno de nove anos com autismo estudava entre alunos de seis anos. Segundo relato dos professores esse aluno possuí um temperamento explosivo as vezes, ou mostra pouco interesse. Mas quando foi feita a oficina sobre Realidade Aumentada ele se mostrou muito aberto e interessado na atividade, já que utilizava um computador e sua Webcam. Ele participou de forma ativa e nos passou a sua opinião sobre o assunto. Também foi possível notar que o aluno se tornou mais receptivo com o palestrante e ajudante, pessoas estranhas para ele até aquele momento. Outra observação feita em relação ao aluno foi que na oficina seguinte, do rondonista que acompanhava o palestrante, ele se mostrou também participativo. Neste sentido, observa-se que realizar atividades para ensino com ferramentas diferenciadas torna-se uma porta de entrada para atingir pessoas com autismo, podendo melhorar a forma de transmitir conhecimentos para eles. 
Operação Rondon: realidade aumentada do projeto museu virtual aplicada na educação infantil

Os professores também se mostraram abertos à mudança para o uso da nova tecnologia, e perceberam a facilidade de utilização de uma aplicação pronta de Realidade Aumentada, pois necessita apenas executá-la. A professora da turma da APAE comentou que "Se fosse criado uma aplicação com o alfabeto e alguns exemplos de palavras dessa forma(usando RA), seria muito útil para ensinar eles(alunos da APAE), ajudando na alfabetização. Também acho que seria legal mostrar alguns personagens em 3D para contar historias.". Podemos notar, assim como a professora comentou, que existem essas e outras possibilidades para explorar a RA na educação. A Ilustração 4 mostra a interação das crianças e da professora com o software. Também é possível notar que o Paraná tem uma grande estrutura em laboratórios de informática nas escolas, como é o caso de todas as escolas frequentadas, que podem ser utilizados também para realização dessas atividades.

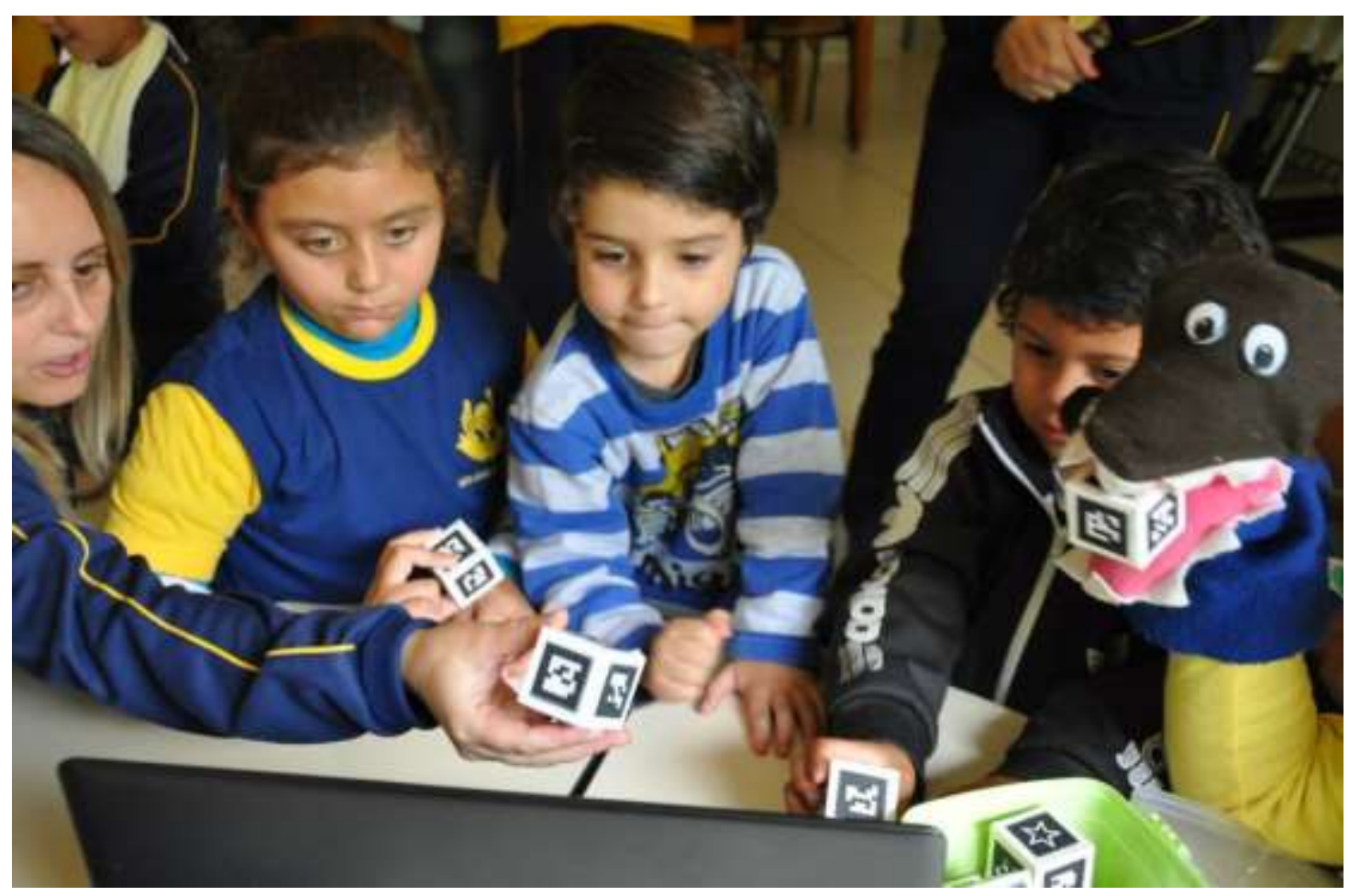

Ilustração 4 - Realização da oficina de RA na Escola APAE São Miguel. Fonte: Elaborado pelos autores, 2015.

Na realização das oficinas, uma das dificuldades encontradas foi a prática da atividade em salas com um número maior que vinte alunos, pois apenas dois computadores e quinze cubos com marcadores estavam disponíveis, necessitando de um controle e organização maior das turmas. Outra dificuldade foi a execução de uma oficina com o intuito educacional infantil, pois durante o curso de Engenharia realizado pelo palestrante a área de docência tanto no ensino normal como também na educação especial não é abrangida. 
Operação Rondon: realidade aumentada do projeto museu virtual aplicada na educação infantil

\section{CONSIDERAÇÕES FINAIS}

A utilização da tecnologia de realidade aumentada se mostra uma ferramenta diferenciada no apoio ao ensino infantil. Tanto em escolas normais como em escolas de educação especiais se mostra viável. A interação dos alunos com o software pareceu natural, entretanto, para eles é difícil entender o que é esta tecnologia (RA). Além disso, foi observado que o software baseado em RA proporcionou aos alunos a interação com a ferramenta, com o professor da turma e com os rondonistas. Sobretudo, proporcionou aos alunos da educação especial um ambiente de aprendizagem lúdico (como no caso do aluno autista).

Um dos desafios encontrados pelo palestrante foi o de se expor a área de educação, já que o curso de Engenharia de Computação não abrange a docência e também o ensino para alunos especiais, pois não sabiam quais seriam suas reações na apresentação da oficina.

Assim, conclui-se que, apesar de resultados satisfatórios quanto ao uso da informática na educação, faz-se necessário observar e levar em consideração o público alvo que irá utilizar estas ferramentas.

\section{REFERÊNCIAS}

AZUMA, R. T. et. al. Recent Advances in Augmented Reality. IEEE Computer Graphics and Applications, v .21, n.6, p. 34-47. 2001.

A Survey of Augmented Reality, UNC Chapel Hill, In Presence: Teleoperators and Virtual Environments, 1997.

BIAGINI, Amalyn Mazzottini et. al. Realidade Aumentada e Crianças: Estudo de Viabilidade para o uso no Museu da Computação da UEPG-Museu Virtual. Disponível em: $<$ http://www.uepg.br/proex/conex/9/anais/9conex anais/153.pdf > Acesso em: 05 ago. 2015.

KIRNER, C. and ZORZAL, E. R. Aplicações Educacionais em Ambientes Colaborativos de Realidade Aumentada. XVI SBIE2005 - Simpósio Brasileiro de Informática na Educação, UFJF, Juiz de Fora - MG. 2005.

LUZ, R et. al.. Análise de Aplicações de Realidade Aumentada na Educação Profissional: Um Estudo de Caso no SENAI DR/GO. 5o. Workshop de Realidade Virtual e Aumentada -

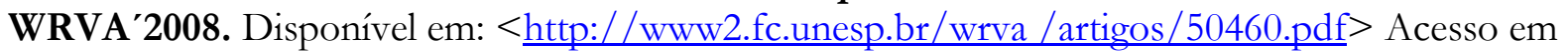
05. ago. 2015. 
Operação Rondon: realidade aumentada do projeto museu virtual aplicada na educação infantil

REALIDADE AUMENTADA. Disponível em: < $\underline{\text { http://www.realidadeaumentada.net/>. }}$ Acesso em: 05 ago. 2015.

UM GUIA SOBRE O USO DE TECNOLOGIAS EM SALA DE AULA. Disponível em:

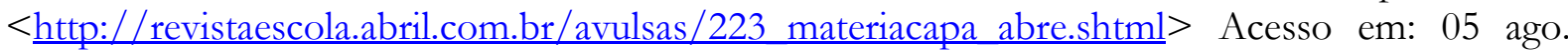
2015. 